\title{
Role of zoledronic acid in the prevention and treatment of osteoporosis
}

\author{
This article was published in the following Dove Press journal: \\ Clinical Interventions in Aging \\ 25 March 20II \\ Number of times this article has been viewed
}

\author{
Agnès Räkel \\ Andrée Boucher \\ Louis-Georges Ste-Marie \\ Endocrinology, Department of \\ Medicine. Centre de recherche du \\ CHUM, Université de Montréal, \\ Montréal, QC, Canada
}

Correspondence: Louis-Georges Ste-Marie

CRCHUM - Hôpital Saint-Luc,

264 East René-Lévesque Blvd, Montreal, Quebec H2X IPI, Canada

Tel +I 5 I4 8908310 ext 35708

Fax + I 5/4 4I27377

Email Ig.ste-marie@umontreal.ca

\begin{abstract}
Taken once a year, intravenous zoledronic acid (Zol) (Reclast ${ }^{\circledR}$ or Aclasta $^{\circledR}$ ) is a third-generation nitrogen-containing bisphosphonate that is effective compared with placebo in reducing the risk of fractures in patients with postmenopausal osteoporosis and recent low-trauma hip fracture. In glucocorticoid-induced osteoporosis, there is no significant difference between Zol and risedronate for new fractures. Improvements in bone mineral density and early reduction of bone remodeling markers are observed in postmenopausal osteoporosis, recent low-trauma hip fracture, and glucocorticoid-induced osteoporosis. Given that Zol is generally well tolerated and very convenient, it is an interesting therapeutic option for aging patients who take multiple oral drugs, who have adherence or gastrointestinal tolerance issues, and who have an indication for oral bisphosphonates. Zol is not recommended for patients with severe renal impairment. Vitamin D deficiency should be corrected before the administration of Zol.
\end{abstract}

Keywords: zoledronic acid, osteoporosis, elderly

\section{Introduction}

\section{Burden of the disease}

According to World Health Organization (WHO) data, osteoporosis affects approximately 75 million people throughout Europe, the US, and Japan. ${ }^{1}$ In the US, osteoporosis occurs in 55\% of the population aged 50 years and over. ${ }^{2}$ Osteoporosis occurs more in women than in men. One in four women over the age of 50 years has osteoporosis in Canada. ${ }^{3}$ Increasing life expectancy means that the prevalence of the disease is likely to increase. It is estimated that, for example, in Canada, by $2041,25 \%$ of the population will be aged 65 years and over. ${ }^{4}$

\section{Definition of osteoporosis}

Osteoporosis is a skeletal disease that is characterized by compromised bone strength predisposing a person to an increased risk of fracture. ${ }^{5}$ Bone strength is a combination of bone density and bone quality. Overall bone strength is difficult to measure in the clinical setting. In the absence of fragility fracture, bone mineral density (BMD), a proxy measure that accounts for up to $70 \%$ of bone strength, is the clinical tool used to diagnose osteoporosis according to the classification of the WHO. BMD that is 2.5 standard deviations or more below the mean BMD of a young adult reference population, which is a $T$-score of -2.5 or less, qualifies for a diagnosis of osteoporosis. ${ }^{6}$ As BMD decreases, fracture risk increases. ${ }^{7}$ Fractures associated with osteoporosis are a major cause of morbidity, disability, mortality, and costs. ${ }^{8}$ Mortality rate is increased by $20 \%$ in the year following a hip fracture. ${ }^{9}$ Furthermore, $50 \%$ of women who suffer from a 
hip fracture will not return to their usual level of functioning and will depend on others for their daily activities; $20 \%$ of them will require long-term care. ${ }^{9}$ Therefore, it is crucial to prevent osteoporosis and fractures.

\section{Risk factors of low BMD}

For patients without fragility fracture, BMD is clearly a good predictor of future fracture risk, and therefore it is important to identify who should be evaluated by BMD. Risk factors for osteoporosis have been identified and are summarized in Table $1 .{ }^{10}$ Every postmenopausal woman and every male aged 50 years and over should be assessed for the presence of risk factors for low BMD (Table 1). A BMD measurement is recommended when at least one risk factor is identified in each age category. ${ }^{11}$

\section{Risk factors of fractures}

Low BMD is an important risk factor for fractures, but many other epidemiological risk factors have been identified and included in a WHO model of 10-year fracture risk prediction, the FRAX ${ }^{\circledR}$ model (World Health Organization Collaborating Centre for Metabolic Bone Diseases, Sheffield, UK). ${ }^{12}$ This model is based on individual patient models that integrate clinical risk factors as well as BMD at the femoral neck. The FRAX model has been developed from studying population-based cohorts from Europe, North America, Asia, and Australia.

According to Osteoporosis Canada, an individual's 10-year absolute fracture risk can also be identified by integrating five key risk factors for fractures: gender, age, BMD, fragility fracture history, and glucocorticoid use. ${ }^{13}$

\section{Strategies in prevention and management of osteoporosis}

Prevention of osteoporosis or low BMD is preferable to treatment because bone microarchitectural changes are mostly irreversible. Strategies for osteoporosis prevention include maximizing peak bone mass during the bone forming years and should favour good nutrition, physical activity, avoidance of cigarette smoking and excess alcohol intake, and minimized administration of drugs known to alter bone health (eg, glucocorticoids, anticonvulsivants). Once the peak bone mass is achieved, strategies to minimize bone loss should also be included. In the US, the Food and Drug Administration (FDA) distinguishes between drugs approved for prevention of osteoporosis and those for treatment. ${ }^{14}$ For prevention of osteoporosis, the FDA suggests that in future studies the study population should consist of ambulatory women who are 1-2 years postmenopausal, aged 45 years or older, and do not have osteoporosis, or ovariectomized women with elevated follicle-stimulating hormone and low estradiol levels. In the aging osteoporotic population with and without fragility fracture, it is too late for maximizing peak bone mass and preventing osteoporosis. Therefore, stabilizing BMD or reducing the rate of bone loss is the primary objective. In the case of patients with fragility fracture, there is established osteoporosis, so secondary fracture prevention should be the main objective. This review will focus on strategies used in i) postmenopausal women, ii) women and men with recent low-trauma hip fracture, and iii) glucocorticoid-treated patients to prevent bone loss and fractures. Strategies used in idiopathic male osteoporosis and in men on androgen deprivation therapy (ADT) will also be reviewed briefly. Among the therapeutic agents available for the prevention of fractures and treatment of osteoporosis, bisphosphonates are the most commonly used drugs. Less than $1 \%$ of oral bisphosphonates are absorbed orally. Therefore, oral bisphosphonates must be taken on an empty stomach, and patients should remain fasting for at least 30 minutes in order to maximize their absorption. ${ }^{15}$ So oral bisphosphonates have to be taken when getting up in morning and, in addition, patients should not lie down after their intake, in order to avoid oesophageal irritation. These constraints have

Table I Indications for measuring bone mineral density

\begin{tabular}{lll}
\hline Age $<\mathbf{5 0}$ years & Age $\mathbf{5 0 - 6 4}$ years & Age $\geq \mathbf{6 5}$ years \\
\hline Fragility fracture & Fragility fracture after age 40 years & All men and women \\
Prolonged use of glucocorticoids & Prolonged use of glucocorticoids or other high-risk medications & \\
Use of high-risk medications & Parental hip fracture & \\
Hypogonadism or premature menopause (age $<45$ years) & Vertebral fracture or osteopenia identified on radiography & \\
Malabsorption syndrome & High alcohol intake or current smoking & Low body weight ( $<60 \mathrm{~kg})$ or major weight loss \\
Chronic inflammatory conditions & $(>10 \%$ of body weight at age 25 years) & \\
Primary hyperparathyroidism & Other disorders strongly associated with &
\end{tabular}
loss and/or fracture

Adapted from Papaioannou A, Morin S, Cheung AM, et al. (C) 2010. CMAJ. ${ }^{10}$ This work is protected by copyright and the making of this copy was with the permission of Access Copyright. Any alteration of its content or further copying in any form whatsoever is strictly prohibited unless otherwise permitted by law. 
raised adherence issues. Poor adherence to oral bisphosphonates has been shown to be associated with suboptimal fracture reduction and prevention. ${ }^{16,17}$ Weekly and monthly oral or intravenous (IV) bisphosphonate regimens have been developed and approved to address this issue. A single infusion of IV zoledronic acid (Zol) $\left(\right.$ Reclast $^{\circledR}$, Aclasta $^{\circledR}$; Novartis Pharmaceuticals Corporation, East Hanover, NJ, USA), a third-generation bisphosphonate, has been conceived to allow better tolerance and better adherence to bisphosphonate therapy.

\section{Zoledronic acid}

\section{Clinical pharmacology}

\section{Mechanism of action}

Zol is a member of the nitrogen-containing bisphosphonates class and acts on bone in a potent way to decrease osteoclastmediated bone resorption. ${ }^{18}$ Like other bisphosphonates, Zol has a high affinity for mineralized bone and binds to the calcium phosphate bone mineral hydroxyapatite, ${ }^{19}$ with preferential localization at sites of high bone turnover. In vitro, when compared with alendronate, ibandronate, risedronate, etidronate, and clodronate, Zol has the highest affinity for hydroxyapatite. ${ }^{19}$ Several independent studies have confirmed that an enzyme of the mevalonate pathway of lipid biosynthesis (farnesyl pyrophosphate synthase [FPP]) is the major enzymatic target of Zol. Zol inhibits FPP, which is critical for the regulation of various cell processes that are important for osteoclast function. ${ }^{20}$ Inhibition of such an enzyme could be responsible for inhibition of osteoclast-mediated bone resorption, as well as osteoclast apoptosis. ${ }^{21}$ According to in vitro studies, Zol appears to inhibit FPP 3-, 7-, 17-, and 67-fold more effectively than risedronate, ibandronate, alendronate, and pamidronate, respectively. ${ }^{20}$

\section{Pharmacokinetic profile Distribution}

There are currently no pharmacokinetic data available for patients with postmenopausal osteoporosis (PMO) or recent low-trauma hip fracture. Data in this section are from studies in patients with bone metastases in whom single and/or multiple IV infusions of Zol of 5 or 15 minutes' duration were administered. ${ }^{22}$ However, as administration of singledose $\mathrm{Zol}$ is recommended in patients with PMO, this section focuses on a single-dose pharmacokinetic profile. Peak Zol plasma concentrations ( $\mathrm{Cmax}$ ) are reached at the end of the infusion period, after which the Zol concentration decreases rapidly, reaching concentrations to $<1 \%$ of Cmax 24 hours postinfusion. The drug is $43 \%-55 \%$ plasma protein bound independent of concentration. ${ }^{23}$

\section{Metabolism and excretion}

Zol is not metabolized in humans; it is excreted intact via the kidney. An average of $39 \%$ of the administered Zol is excreted in the urine within the first 24 hours. ${ }^{23}$ The rest of the dose is presumed to be bound to bone and released back into the circulation very slowly. The clearance of Zol is dependent on creatinine clearance (CrCL). However, no significant change in exposure to Zol was noted in patients with mild (50-80 $\mathrm{mL} / \mathrm{min})$ to moderate renal impairment (35-50 $\mathrm{mL} / \mathrm{min}$ ) compared with patients with normal renal function. ${ }^{24}$ Dosage is not adjusted for mild or moderate renal failure, but $\mathrm{Zol}$ is not recommended in patients with severe renal impairment ( $<35 \mathrm{~mL} / \mathrm{min}$ ) because of the lack of data in this population. ${ }^{23}$ No effect has been shown on cytochrome P450. The pharmacokinetics of Zol were not affected by gender, race, or age in patients who ranged in age from 38 to 84 years. $^{23}$

\section{Pharmacodynamic effects}

Zol reduces rapidly the rate of bone turnover, first by reducing the resorption and then the formation. Biochemical markers of bone resorption were more suppressed by Zol compared with placebo ${ }^{25}$ and alendronate ${ }^{26}$ in women with $\mathrm{PMO}^{25}$ or low $\mathrm{BMD}^{26}$ in studies of 24 weeks ${ }^{\text {'26 }}$ or 3 years ${ }^{25}$ duration. In patients with $\mathrm{PMO}$, the effect of $\mathrm{Zol}$ treatment on markers of bone resorption (serum $\beta$-C-telopeptides $[\beta-\mathrm{CTx}]$ ) and bone formation (bone specific alkaline phosphatase [BSAP], serum N-terminal propeptide of type 1 collagen $[\mathrm{P} 1 \mathrm{NP}])$ was evaluated in patients at periodic intervals. Treatment with a $5 \mathrm{mg}$ annual dose of Zol reduced bone turnover markers to the premenopausal range with an approximate $55 \%$ reduction in $\beta$-CTx, a $29 \%$ reduction in BSAP, and a 52\% reduction in P1NP over 36 months. There was no progressive reduction of bone turnover markers with repeated annual dosing. ${ }^{25}$ Zol produced more marked and rapid decrease in markers than oral alendronate $70 \mathrm{mg}$ once weekly in patients with osteoporosis or low BMD. ${ }^{26}$ The nadir of each resorption marker was reached at 7 days and for formation markers at 12 weeks. ${ }^{26}$ Subgroup analyses of the main trial of Zol in PMO ${ }^{25}$ HORIZON-PFT (Health Outcomes and Reduced Incidence with Zoledronic Acid Once Yearly - Pivotal Fracture Trial), revealed that the changes in bone markers in patients treated with Zol versus placebo were not influenced by age. ${ }^{27,28}$

\section{Efficacy}

\section{Postmenopausal women}

The efficacy of Zol was demonstrated in HORIZON-PFT for the treatment of osteoporosis in postmenopausal women. ${ }^{25}$ 
HORIZON-PFT was a randomized, double-blind, placebo-controlled, multinational study of 7736 women aged $65-89$ years. The majority of patients were $70-74$ years old (38\% in both groups). Inclusion criteria were either a femoral neck BMD $T$-score $\leq-1.5$ and at least two mild or one moderate existing vertebral fracture(s), or a femoral neck BMD $T$-score $\leq-2.5$ with or without evidence of an existing vertebral fracture(s). The trial excluded patients previously treated with strontium, parathyroid hormone, or sodium fluoride. Zol, as a single $5 \mathrm{mg}$ infusion over 15 minutes, was administered yearly for 3 consecutive years.

\section{Fractures}

In HORIZON-PFT, the two primary efficacy endpoints were the incidence of morphometric vertebral fractures at 3 years and the incidence of hip fractures over a median duration of 3 years. Patients were divided into two strata (stratum 1 and 2). In stratum 1, 6084 women were not receiving concomitant osteoporosis therapy at baseline. In stratum 2, 1652 patients were receiving antiosteoporosis therapy at baseline. Concomitant therapy included calcitonin, raloxifene, tamoxifen, hormone replacement therapy, dehydroepiandrosterone, ipriflavone, medroxyprogesterone, and tibolone but excluded bisphosphonates. All women received 1000-1500 mg of calcium plus 400-1200 IU of vitamin D each day.

As shown in Table 2, IV Zol 5 mg once yearly significantly reduced the risk of new morphometric vertebral fracture by $70 \%$ (absolute reduction in fracture incidence $7.6 \%$ over 3 years when compared with placebo in patients in stratum 1). Significant reduction in the relative risk (RR) of new vertebral fracture was seen as soon as 1 year (relative risk reduction $[R R R]=60 \%$ ) and after 2 years of treatment $(\mathrm{RRR}=71 \%)$.

IV Zol also significantly reduced the risk of new hip fractures by $41 \%$ at 3 years compared with placebo in the overall patient population (stratum 1 and 2) (Table 2). The hip fracture event rate was $1.45 \%$ for Zol-treated patients and $2.5 \%$ for placebo-treated patients. According to the monograph, the reductions in vertebral and hip fractures over 3 years were consistent and significantly reduced independent of age, number of vertebral fractures at baseline, geographical region, race, baseline body mass index, femoral neck BMD $T$-score, or prior use of bisphosphonates. Specifically, in patients aged 75 years and older, Zol-treated patients had a $60 \%$ decrease in RRR for vertebral fractures compared with placebo patients $(P<0.0001)$. IV Zol $5 \mathrm{mg}$ once yearly was also effective in reducing the risk of all secondary endpoints such as clinical vertebral fractures (RRR of 77\%), any clinical fracture (RRR of 33\%), and nonvertebral fracture (RRR of $25 \%$ ) in the overall patient population (stratum 1 and 2) during the 3-year treatment period (Table 2). The risk of multiple morphometric vertebral fractures was also significantly reduced by $89 \%$ when compared with placebo $(0.2 \%$ vs $2.3 \%$ of patients $)$ in patients without any concomitant osteoporosis treatment (stratum 1).

\section{BMD}

In HORIZON-PFT, the secondary efficacy measure included the percentage change from baseline in lumbar spine, femoral neck, and total hip BMD. ${ }^{29}$ Zol significantly

Table 2 Effects of zoledronic acid on incident fractures

\begin{tabular}{|c|c|c|c|c|}
\hline Study & Endpoint & $\begin{array}{l}\text { Absolute reduction } \\
\text { in fracture incidence \% } \\
(95 \% \mathrm{Cl})\end{array}$ & $\begin{array}{l}\text { Relative risk reduction } \\
\text { in fracture incidence \% } \\
(95 \% \mathrm{Cl})\end{array}$ & $P$ value \\
\hline \multicolumn{5}{|c|}{$\begin{array}{l}\text { Postmenopausal women } \\
\text { (HORIZON-PFT) }\end{array}$} \\
\hline & \multicolumn{4}{|l|}{ Vertebral fracture } \\
\hline & Over 12 months & 2.2 & $60(43-72)$ & $<0.0001$ \\
\hline & Over 24 months & 5.5 & $71(62-78)$ & $<0.0001$ \\
\hline & Over 36 months & 7.6 & $70(62-76)$ & $<0.0001$ \\
\hline & \multicolumn{4}{|l|}{ Hip fracture } \\
\hline & Over 36 months & I.I & $4 \mid(17-58)$ & $P=0.0024$ \\
\hline & \multicolumn{4}{|l|}{ Nonvertebral fractures } \\
\hline & Over 36 months & 2.7 & $25(13-36)$ & $<0.0001$ \\
\hline \multirow{2}{*}{\multicolumn{5}{|c|}{$\begin{array}{l}\text { Patients with hip fracture } \\
\text { (HORIZON-RFT) }\end{array}$}} \\
\hline & & & & \\
\hline & Any clinical fracture & 5.3 & $35(16-50)$ & 0.001 \\
\hline & Clinical vertebral fracture & 2.1 & $46(8-68)$ & 0.02 \\
\hline & Nonvertebral fracture & 3.1 & $27(2-45)$ & 0.03 \\
\hline & Hip fracture & 1.5 & $30(19-59)$ & 0.18 \\
\hline
\end{tabular}


increased BMD at the lumbar spine, total hip, and femoral neck compared with placebo at 6, 12, 24, and 36 months (Table 3).

\section{Histology, remodeling markers, and bone strength}

The effect of Zol on bone histology was also evaluated. ${ }^{25,29}$ Biopsies taken in patients after 3 years of Zol had significantly lower median activation frequency, mineralizing surfaces, and bone formation rate (volume referent) than biopsies from patients in the placebo group. Even if bone turnover was suppressed, bone remodeling was still present in all but one of 82 iliac crest biopsies and in all 70 biopsies of the placebo recipients. ${ }^{30}$ Bone quality did not appear to be impaired in PMO patients in the Zol group. No evidence of woven bone, marrow fibrosis, or cellular toxicity was demonstrated in bone biopsies from these patients. ${ }^{30}$ In HORIZON-PFT, annual injections of Zol reduced remodeling markers in the premenopausal range, with a significant response persisting after the third infusion. ${ }^{27}$ Zol was also effective in improving some indices of bone strength in PMO in the HORIZON-PFT, as measured by quantitative computed tomography scan. ${ }^{31}$ After 3 years, Zol patients had significantly increased compression strength indices at the femoral neck and trochanter, and similar bending strength indices at the femoral neck compared with placebo. Improvement in cortical bone was also demonstrated in the Zol group. ${ }^{31}$ In another study looking at the biopsies obtained during HORIZON, the authors used Raman microspectroscopy (a vibrational spectroscopic technique that analyzes undecalcified bone tissue) to determine the effect of Zol on bone material properties, such as the mineral/ matrix ratio at similar tissue age. This study suggests that once-yearly administration of IV Zol for 3 years in humans exerts effects on bone matrix formation quality, in addition to the known antiresorptive effects and independently of bone turnover. ${ }^{32}$

Table 3 Effects of zoledronic acid on bone mineral density (BMD)

\begin{tabular}{llll}
\hline Study & Location & $\begin{array}{l}\text { BMD change relative } \\
\text { to treatment with } \\
\text { placebo }\end{array}$ & P value \\
\hline HORIZON-PFT & & & \\
at 36 months & Lumbar spine & $+6.7 \%$ & $<0.000$ I \\
& Femoral neck & $+5.1 \%$ & $<0.000$ I \\
& Total hip & $+6.0 \%$ & $<0.000$ I \\
HORIZON-RFT & & & $<0.001$ \\
over 24 months & & & $<0.001$ \\
\hline & Total hip & $+5.4 \%$ &
\end{tabular}

Abbreviation: BMD bone mineral density.

\section{Postmenopausal women with low bone mass}

Zol has also been approved for the prevention of PMO during a 2-year period. In this 2-year double-blind, randomized, multicenter, clinical study $(\mathrm{n}=581)$, three treatment arms were compared: group 1, Zol $5 \mathrm{mg}$ IV at randomization and at month 12 (Zol $2 \times 5 \mathrm{mg})$; group 2, Zol $5 \mathrm{mg}$ IV only at randomization and placebo at month $12(\mathrm{Zol} 1 \times 5 \mathrm{mg})$; or group 3, placebo at randomization and at month 12 (placebo). Both Zol regimens (groups 1 and 2) significantly increased mean lumbar spine BMD compared with placebo (group 3) at month 12 and 24. Similarly, greater increases in hip BMD were observed at month 12 and 24 in groups 1 and 2 compared with those in group 3. Both Zol regimens significantly reduced bone markers. The yearly Zol (group 1, ie, Zol $2 \times 5 \mathrm{mg}$ ) administration suppressed the bone markers in a more sustained way during the second year than the single dose regimen (group 2, ie, Zol $1 \times 5 \mathrm{mg}$ ). Therefore, the recommended prophylactic regimen of $\mathrm{Zol}$ is a single dose of $5 \mathrm{mg}$ every 2 years administered IV during a period of 15 minutes. Daily supplementation with elemental calcium 500-1000 mg plus 400-800 IU vitamin $\mathrm{D}$ is recommended. ${ }^{33}$

In a double-blind, randomized, placebo-controlled trial over 2 years, 50 postmenopausal women with low bone mass were randomized to Zol $5 \mathrm{mg} \times 1$ versus placebo. Compared with placebo, Zol decreased levels of remodeling markers by $38 \%$ for 2 years; after 2 years, BMD was higher in the Zol group than in the placebo group (+5.7\% at lumbar spine, $3.9 \%$ at proximal femur, and $1.7 \%$ at the total body). ${ }^{34}$

\section{Patients with hip fracture (men and women)}

The clinical efficacy of $\mathrm{Zol}$ in patients with a recent lowtrauma hip fracture was investigated in a large randomized, double-blind, placebo-controlled, multicenter 5-year study, HORIZON-Recurrent Fracture Trial (RFT). ${ }^{35}$

\section{Fractures}

In HORIZON-RFT, 2127 men and women aged $\geq 50$ years with low-trauma hip fracture were randomly assigned to receive yearly Zol $(5 \mathrm{mg})(\mathrm{n}=1065)$ or placebo $(\mathrm{n}=1062)$ within 3 months of surgical repair. ${ }^{35}$ Exclusion criteria included previous treatment with strontium or sodium fluoride, a metabolic disease of the bone other than osteoporosis, cancer, a $\mathrm{ClCr}<30 \mathrm{~mL} / \mathrm{min}$, a serum calcium level of $>2.8$ or $<2.0 \mathrm{mmol} / \mathrm{L}$, or a life expectancy of $<6$ months. A washout period was included for patients 
who had previously received bisphosphonates or parathyroid hormone. ${ }^{35}$ Subjects also received vitamin D (50,000-125,000 IU) 14 days prior to infusion, if $25(\mathrm{OH})$ vitamin $\mathrm{D}$ was $<15 \mathrm{ng} / \mathrm{dL}$ or unknown, and 800 to $1200 \mathrm{IU}$ daily thereafter and calcium. Concomitant treatment with selective estrogen receptor modulators, nasal calcitonin, tibolone, hormone replacement therapy, and external hip protectors was allowed. After a median follow-up of 1.9 years, new clinical fractures occurred in $8.6 \%$ and $13.9 \%$ of patients in the Zol and placebo groups, representing a significant decrease in RRR of $35 \%$ (Table 2). There was also a 46\% RRR in clinical vertebral fracture and a 27\% RRR in nonvertebral fractures (Table 2). The RR for a subsequent hip fracture was reduced by $30 \%$, but this did not reach statistical significance, most likely due to the small number of cases.

\section{BMD}

As shown in Table 3, Zol $5 \mathrm{mg}$ resulted in significant increases in BMD for the total hip and femoral neck (5.4\% at the total hip and $4.3 \%$ at the femoral) over 24 months as compared with placebo) in males and females analyzed together. In the male subgroup, a greater increase was demonstrated in total hip BMD at month 24 with Zol $(3.81 \% ; P=0.0021)$ versus placebo, suggesting a comparable effect in both genders. ${ }^{36}$ This trend continued to be observed at 36 months.

\section{Glucocorticoid-induced osteoporosis}

The efficacy and safety of Zol in the glucocorticoid-induced osteoporosis (GIO) trial were assessed in a randomized, multicenter, double-blind, stratified (treatment and prevention), active-controlled study of 833, mainly Caucasian, men and women aged $18-85$ years treated with $>7.5 \mathrm{mg} /$ day oral prednisone or equivalent. ${ }^{37}$ The prevention group was composed of patients who were treated with glucocorticoids for less than 3 months prior to randomization. Patients in the treatment group were treated with glucocortiocids for 3 months or more. Patients were randomized either to Zol $5 \mathrm{mg}$ or oral risedronate. It was a noninferiority trial. All patients were on elemental calcium $1000 \mathrm{mg}$ plus vitamin D 400-1000 IU per day. Results showed that Zol was noninferior and superior to risedronate for increase of lumbar spine BMD in the treatment $(+4.06 \%$ vs $2.71 \%)$ and prevention groups $(2.6 \%$ vs $0.64 \%)$ after 12 months. At the lumbar spine, the increase in BMD was statistically significant for postmenopausal women and men but not for premenopausal women. Concentrations of biomarkers for bone resorption and formation were reduced by both drugs but more importantly at 12 months for patients on Zol than for patients on risedronate in both the prevention and treatment groups. The frequency of new vertebral fractures was very low in Zol and risedronate patients with no significant difference between the two groups. ${ }^{37}$

\section{In males}

\section{Idiopathic osteoporosis}

A recent study by Orwoll et al compared the efficacy and safety of a once-yearly IV infusion of Zol with weekly oral alendronate in men with osteoporosis. ${ }^{38}$ This study was a multicenter, randomized, double-blind, double-dummy, activecontrolled efficacy trial in a male only study of 302 men with osteoporosis aged 25-86 years (mean age 64 years) in which patients were randomized for 2 years to either $\mathrm{Zol}$ $5 \mathrm{mg}$ once yearly or to oral alendronate $70 \mathrm{mg}$ weekly. All participants received $1000 \mathrm{mg}$ calcium plus 800-1000 IU vitamin D supplementation per day. The Zol infusion was shown to be noninferior to weekly alendronate for the percentage change in lumbar spine BMD at month 24 relative to baseline (Zol 6.1\% vs alendronate 6.2\%). The differences in BMD increases at lumbar spine, total hip, femoral neck, and trochanter at month 6,12 , or 24 were not statistically significant between $\mathrm{Zol}$ and alendronate.

\section{On androgen deprivation therapy (ADT)}

ADT for prostate cancer is associated with accelerated bone loss and increased fracture risk. ${ }^{39} \mathrm{Zol} 4 \mathrm{mg}$ IV every 3 months for four treatments has been demonstrated to prevent bone loss in patients initiating $\mathrm{ADT}^{40}$ and to improve BMD in patients with prostate cancer (without metastasis) on ADT for 1 year or less or for greater than 1 year. ${ }^{41}$ It is important to note that no data exist on the effect of Zol $5 \mathrm{mg}$ once yearly in such population.

\section{Safety}

\section{Hypocalcemia}

In HORIZON-PFT, between 9 and 10 days following the infusion, hypocalcemia (serum calcium $<2.075 \mathrm{mmol} / \mathrm{L}$ ) was reported in $1.27 \%$ of Zol recipients versus $0.03 \%$ of placebo recipients. ${ }^{25}$ In HORIZON-RFT, the incidence of hypocalcemia was also low $(0.3 \%$ in the Zol group vs $0 \%$ in the placebo group). ${ }^{35}$ It is recommended that all patients should have their serum calcium levels and vitamin D levels assessed before initiating the treatment with Zol. Pre-existing hypocalcemia is a contraindication to Zol and should be corrected before the infusion with calcium and vitamin D. In addition, sufficient vitamin $\mathrm{D}$ supplementation to ensure and maintain adequate serum $25(\mathrm{OH})$ vitamin D levels should be given before and after Zol infusion. 


\section{Atypical subtrochanteric fractures}

Recent case series have suggested the possibility that lowtrauma subtrochanteric hip fractures may be increased in long-term users of bisphosphonates. ${ }^{42-48}$ Although the optimal duration of bisphosphonate use for osteoporosis is unknown, these atypical fractures may be related to long-term bisphosphonate use. The FDA issued a Drug Safety Communication in October 2010 and will require a new Limitations of Use statement in the Indications and Usage section of the labels for these drugs. This statement will describe the uncertainty of the optimal duration of use of bisphosphonates for the treatment and/or prevention of osteoporosis. ${ }^{49}$

As compared with placebo, the relative hazard of atypical subtrochanteric fracture was 1.50 (95\% confidence interval 0.25-9.00, ie, nonsignificant) for Zol use in HORIZON-PFT. ${ }^{25}$ After 3 years of treatment, Zol did not seem to be associated with an increased risk of atypical subtrochanteric fractures..$^{50}$ However, this outcome is very rare and is very difficult to assess in a single clinical trial.

\section{Osteonecrosis of the jaw}

Over recent years, cases of osteonecrosis of the jaw (ONJ) have emerged in patients receiving bisphosphonates. In the majority of cases, patients with ONJ were patients with multiple myeloma or metastatic breast cancer treated with IV Zol or pamidronate. ${ }^{51}$ There has been no case of spontaneous reports of ONJ in either HORIZON trials..$^{25,35}$ In HORIZON-PFT, blinded adjudication/expert review of adverse events identified one $\mathrm{Zol}$ and one placebo recipient with symptoms compatible with ONJ (according to the adjudication committee definition: exposed bone in the maxillofacial area with delayed healing for more than 6 weeks despite appropriate care).$^{52}$ However, long-term studies are needed in this area. ONJ has been reported rarely in the treatment of PMO with Zol as well as with other oral and IV bisphosphonates. ${ }^{51,53}$ The majority of the cases have been reported where there had been dental procedures. A routine dental examination is recommended prior to treatment. Patients with associated risk factors (cancer, chemotherapy, glucocorticoids, dental procedure, poor oral hygiene) should have preventive dentistry prior to the infusion. While on treatment, these patients should avoid major dental procedures.

\section{Cardiovascular adverse events}

In HORIZON-PFT, arrhythmia occurred significantly more often in the Zol recipients than in the placebo recipients $(6.9 \%$ vs $5.3 \%, P=0.003){ }^{25}$ Serious atrial fibrillation (needing hospital admission) occurred more often in the Zol-treated patients than in those receiving the placebo $(1.3 \%$ vs $0.5 \%$, $P<0.001) .{ }^{25}$ Among the 50 patients who developed atrial fibrillation in the Zol group, the events occurred more than 30 days after infusion in 47 patients (94\%). This increased incidence has not been confirmed in HORIZON-RFT, the Paget trial, ${ }^{54}$ nor the trial for prevention of PMO ${ }^{33,55}$ In addition, the incidence of any atrial fibrillation was similar between the Zol recipients and the placebo recipients in each of the HORIZON trials. ${ }^{25,35}$ No mechanism has been found to explain this increased incidence of atrial fibrillation. Osteoporosis and atrial fibrillation are diseases that are more common in the elderly and that share some risk factors. After reviewing all the clinical studies involving the various bisphosphonates, the FDA issued a statement in November 2008 that "Across all studies, no clear association between overall bisphosphonate exposure and the rate of serious or non-serious atrial fibrillation was observed". ${ }^{4}$

\section{Renal failure}

Once-yearly Zol was not associated with long-term renal toxicity in patients with $\mathrm{PMO}^{25}$ or a recent low-trauma hip fracture. ${ }^{35}$ After 3 years of treatment, in HORIZON-PFT, Zol and placebo recipients did not differ with regard to mean changes in $\mathrm{CrCL}$, creatinine levels, incidence of renal abnormalities, or estimated $\geq 30 \%$ reduction in CrCL. ${ }^{56}$ The renal tolerability of Zol was also similar to that of placebo in HORIZON-RFT. ${ }^{35}$ However, it is important to note that Zol is contraindicated in patients with severe renal impairment. Moreover, Zol appeared more effective in preventing vertebral fractures in women with normal renal function. ${ }^{1}$ It is of utmost importance that the duration of infusion should not be shorter than 15 minutes, as more rapid infusions have been associated with impairment of renal function in the oncology setting, where other risk factors such as pre-existing renal disease and concomitant use of nephrotoxic drugs can contribute. ${ }^{57-59}$ In addition, patients should be well hydrated before the infusion.

\section{Geriatrics}

HORIZON-PFT and -RFT when taken together included 4761 Zol-treated patients aged 65 years and older and 2083 patients aged 75 years and older. No difference was noted in safety or efficacy according to age. ${ }^{25}$ However, in a subgroup analysis that was preplanned and post hoc, a greater Zol protective effect for vertebral fracture was seen in women of younger age. ${ }^{1}$

In the osteoporosis study in men cited in the monograph, 38.3\% $(n=59)$ of Zol-treated patients were 65 years 
and older and $15.6 \%(\mathrm{n}=24)$ were 75 years and older. ${ }^{23}$ No difference was noted in safety or efficacy according to age neither in this study nor in the GIO trial, ${ }^{37}$ where $27.9 \%$ of Zol-treated patients were 65 years and older and $7 \%$ were 75 years and older.

\section{Ocular adverse events}

Patients who were treated with Zol had an absolute increase of $0.69 \%$ (3.34\% vs $2.65 \%$ ) in inflammatory ocular adverse events (mainly conjunctivitis) in the first 15 days after the infusion. ${ }^{25}$ In HORIZON-RFT, only one case of iritis was reported in the Zol group. ${ }^{35}$ In the male osteoporosis trial, two cases of conjunctivitis and one case of eye pain were reported in the Zol group and one case of iritis in the alendronate group. ${ }^{23,60}$ In the GIO trial, one case of conjunctivitis was reported in the Zol group. ${ }^{37}$

\section{Tolerability}

Zol $5 \mathrm{mg}$ administered via a 15-minute IV infusion was generally well tolerated in patients with $\mathrm{PMO},{ }^{25,29}$ low BMD,${ }^{29}$ male idiopathic osteoporosis, ${ }^{61} \mathrm{GIO},{ }^{37}$ or recent low-trauma hip fracture. ${ }^{35}$ All bisphosphonates, including Zol, have a risk of rare occurrence of severe and sometimes incapacitating pain in the bones, joints, and muscles. This risk of musculoskeletal symptoms has been highlighted by the FDA. The FDA suggests that bisphosphonates should be discontinued if such symptoms appear. ${ }^{49}$

\section{Adverse reactions}

\section{Versus placebo}

The most common adverse events that occurred statistically more in Zol than in placebo patients were athralgias $(23.8 \%$ vs $20.4 \%$ ), pyrexia ( $17.9 \%$ vs $3.7 \%$ ), flu-like symptoms ( $8.8 \%$ vs $2.7 \%)$, nausea ( $8.5 \%$ vs $5.2 \%)$, bone pain $(5.8 \%$ vs $2.3 \%$ ), and chills (5.4\% vs 1\%) in HORIZON-PFT. ${ }^{25}$ Many of these symptoms were reported in the 3 days following the infusion and occurred significantly more in the Zol group than in the placebo recipients. In HORIZON-RFT, patients received paracetamol at the time of infusion and after the infusion. In this study, only pyrexia and myalgia occurred significantly more in the Zol group than in the placebo group but at a lower rate $(8.7 \%$ vs $3.1 \%) .{ }^{37}$ The symptoms usually resolved within 3 days.

\section{Versus alendronate or risedronate}

The percentage of patients experiencing adverse events is comparable in patients receiving Zol (single dose) and oral alendronate or risedronate once weekly, with the exception of a higher incidence of postinfusion symptoms in the 3 days following the infusion. ${ }^{37,61}$

\section{Follow-up}

Calcium

It is suggested that all patients should have a calcium and vitamin D level measured before treatment with Zol. In the PMO trial, patients received 1000-1500 mg of elemental calcium plus $400-1200 \mathrm{IU}$ of vitamin D. ${ }^{25}$ In the trial on the prevention of fractures in patients who suffered a recent low-trauma hip fracture, subjects also received vitamin D (50,000-125,000 IU) 14 days prior to infusion if $25(\mathrm{OH})$ vitamin $\mathrm{D}$ was $<15 \mathrm{ng} / \mathrm{dL}$ or unknown and $800-1200 \mathrm{IU}$ daily thereafter and calcium. ${ }^{35}$

\section{Renal function}

Given that bisphosphonates are not recommended for patients with $\mathrm{CrCL}<30$, a measure of creatinine is recommended before each infusion. Renal toxicity has been reported with some IV bisphosphonates, including Zol. This situation was mainly observed in cancer patients when the duration of the infusion was shorter than 15 minutes. ${ }^{59}$ Patients should be well hydrated prior to the infusion.

\section{Patient satisfaction and quality of life}

Once-yearly IV administration of bisphosphonate appears to be preferred over once-weekly oral administration, according to data from the 1-year study in patients with PMO or low BMD previously treated with alendronate. ${ }^{29}$ In this study, $78.7 \%$ patients preferred a once-yearly IV regimen, 9\% preferred a once-weekly oral regimen, and $11.8 \%$ considered both treatment regimens to be comparable.

Compliance to osteoporosis treatment regimens is poor in general. ${ }^{62}$ The fact that Zol is administered once yearly in a 15-minute infusion could help with regard to patient adherence to therapy compared with other bisphosphonates or other osteoporosis treatments. With the Zol treatment regimen, the medication is completely absorbed, and its efficacy at protecting the patient against fracture lasts for 1 year.

\section{Place of zoledronic acid in the treatment and prevention of osteoporosis}

The management of skeletal health in the elderly should be focused toward minimizing bone loss and prevention of fractures. All patients should receive lifestyle education (physical activity, avoidance of cigarettes and alcohol) and nonpharmacological therapy (adequate calcium intake, 
vitamin D) in order to preserve BMD and strength. ${ }^{2}$ For elderly patients with low bone mass, GIO, or osteoporosis who are at increased risk of fractures, bisphosphonates are first-line therapy (for women and men). However, for raloxifene, other considerations such as risk of cancer, venous thromboembolism, and hot flashes must be considered (Table 4). If bisphosphonates are indicated, Zol should be considered an alternative for patients who cannot tolerate oral bisphosphonates, patients with significant gastroesophageal reflux or peptic ulcer disease, and patients with Barrett's esophagus or who have difficulty with dosing requirements (such as remaining fasting and sitting upright for 30-60 minutes and/or swallowing a pill). Compared with other bisphosphonates, Zol has the highest affinity for bone

Table 4 Comparison of different agents used in the treatment of postmenopausal osteoporosis, GIO, or male osteoporosis

\begin{tabular}{|c|c|c|c|c|}
\hline Drug & Route of administration & Adverse effects & Contraindications & Indications \\
\hline Bisphosphonates & & & $\begin{array}{l}\text { Severe renal failure, } \\
\text { hypocalcemia, } \\
\text { hypersensitivity, } \\
\text { pregnancy }\end{array}$ & PMO, GIO, MO \\
\hline \multirow[t]{6}{*}{ Zoledronic acid } & IV infusion once yearly & Transient postinfusion & & \\
\hline & & influenza-like illness, & & \\
\hline & & concerns about & & \\
\hline & & arrhythmia and serious & & \\
\hline & & atrial fibrillation, mild & & \\
\hline & & transient hypocalcemia & & \\
\hline \multirow[t]{2}{*}{ Ibandronate } & IV injection 3 monthly & Transient postinjection & & No hip fracture protection \\
\hline & & influenza-like illness & & for oral ibandronate \\
\hline \multirow[t]{6}{*}{ Alendronate } & Oral once monthly & & Caution in patients with & \\
\hline & & & GERD or peptic ulcer & \\
\hline & & & disease & \\
\hline & Oral tablet once daily; & & Contraindication in Barrett's & \\
\hline & once weekly & & esophagus and inability to sit & \\
\hline & & & upright for $30-60$ minutes & \\
\hline Risedronate & Oral tablet once daily, & & & \\
\hline & once weekly, once twice & & & \\
\hline & weekly, once monthly & & & \\
\hline \multicolumn{5}{|c|}{ Selective estrogen receptor modulators } \\
\hline Raloxifene & Oral tablet once daily & Hot flashes and leg & VTE past or present, & PMO, no hip fracture \\
\hline & & cramps, concerns & liver failure, moderate & protection \\
\hline & & about VTE & or severe renal failure, & \\
\hline & & & patients with coronary & \\
\hline & & & heart disease: increased & \\
\hline & & & risk of stroke or death & \\
\hline \multicolumn{5}{|l|}{ Anabolic agents } \\
\hline \multirow[t]{8}{*}{ PTH (I-34, I-84) } & Subcutaneous injection & & Severe renal or liver & PMO, GIO, MO \\
\hline & once daily & & impairment, metabolic & \\
\hline & & & bone disease, previous & \\
\hline & & & radiation therapy involving & \\
\hline & & & the skeleton, hypercalcemia, & \\
\hline & & & elevation of ALP, bone & \\
\hline & & & metastases, skeletal & \\
\hline & & & malignancies & \\
\hline \multicolumn{5}{|l|}{ Others } \\
\hline \multirow[t]{3}{*}{ Strontium } & Oral suspension & Severe hypersensitivity & Severe renal failure, & \\
\hline & once daily & syndromes have been & past VTE? & \\
\hline & & described and VTE, diarrhea & & \\
\hline Calcitonin & Intranasal & & & PMO, GIO, MO \\
\hline $\begin{array}{l}\text { Monoclonal antibody } \\
\text { against RANKL }\end{array}$ & & & & \\
\hline Denosumab & $\begin{array}{l}\text { Subcutaneous injections } \\
\text { once every } 6 \text { months }\end{array}$ & $\begin{array}{l}\text { Concerns about immune } \\
\text { system (skin infection, } \\
\text { diverticulitis, pneumonia, } \\
\text { appendicitis) }\end{array}$ & & PMO, GIO, MO \\
\hline
\end{tabular}

Abbreviations: ALP, alkaline phosphatase; GERD, gastroesophageal reflux disease; GIO, glucocorticoid-induced osteoporosis; IV, intravenous; MO, male osteoporosis; PMO, postmenopausal osteoporosis; PTH, parathyroid hormone; RANKL, receptor activator of nuclear factor kappa-B ligand; VTE, venous thromboembolism. 
mineral and is the most potent inhibitor of FPP. Adherence to osteoporosis regimens is poor. Because Zol is administered once yearly in a clinical setting, it may help patients with compliance. Further clinical experience is needed to confirm that these characteristics can have an impact on fracture protection. Special attention should be given to vitamin D deficiency treatment before the infusion. Bisphosphonates and Zol, in particular, are generally not recommended for patients with $\mathrm{CrCL}<35 \mathrm{~mL} / \mathrm{min}$. Currently, there is no consensus with regard to the duration of bisphosphonate treatment.

\section{Acknowledgment}

The authors would like to thank Marylene Joyal for her expert secretarial assistance in the preparation of the manuscript.

\section{Disclosure}

Dr Ste-Marie has received grants and research support, worked as a consultant and acted as an advisor for Alliance for better bone health (Procter \& Gamble Pharmaceuticals and sanofi aventis Canada Inc.), Amgen Canada, AstraZeneca Inc, Eli Lilly Inc, GlaxoSmith Kline Inc, Merck Frost, Novartis Pharma Inc, Servier Inc, Pfizer Canada Inc, Zelos Therapeutics Inc and Warner Chilcott. Drs Räkel and Boucher report no conflicts of interest in this work.

\section{References}

1. Eastell R, Black DM, Boonen S, et al. Effect of once-yearly zoledronic acid five milligrams on fracture risk and change in femoral neck bone mineral density. J Clin Endocrinol Metab. 2009;94(9):3215-3225.

2. National Osteoporosis Foundation. Clinician's Guide to Prevention and Treatment of Osteoporosis. Washington, DC: National Osteoporosis Foundation; 2008.

3. Hanley DA, Josse RG. Prevention and management of osteoporosis: consensus statements from the Scientific Advisory Board of the Osteoporosis Society of Canada. 1. Introduction. CMAJ. 1996;155(7):921-923.

4. Papadimitropoulos EA, Coyte PC, Josse RG, Greenwood CE. Current and projected rates of hip fracture in Canada. CMAJ. 1997;157(10): 1357-1363.

5. National Institutes of Health Consensus Development Panel on Osteoporosis, Prevention, Diagnosis and Therapy. Osteoporosis prevention, diagnosis, and therapy. JAMA. 2001;285(6):785-795.

6. Genant HK, Cooper C, Poor G, et al. Interim report and recommendations of the World Health Organization Task-Force for Osteoporosis. Osteoporos Int. 1999;10(4):259-264.

7. Johnell O, Kanis JA, Oden A, et al. Predictive value of BMD for hip and other fractures. J Bone Miner Res. 2005;20(7):1185-1194.

8. Cauley JA, Thompson DE, Ensrud KC, et al. Risk of mortality following clinical fractures. Osteoporos Int. 2000;11(7):556-561.

9. Chrischilles EA, Butler CD, Davis CS, Wallace RB. A model of lifetime osteoporosis impact. Arch Intern Med. 1991;151(10):2026-2032.

10. Papaioannou A, Morin S, Cheung AM, et al. 2010 clinical practice guidelines for the diagnosis and management of osteoporosis in Canada: summary. CMAJ. 2010;182(17):1864-1873.

11. Brown JP, Josse RG. 2002 clinical practice guidelines for the diagnosis and management of osteoporosis in Canada. CMAJ. 2002;167(90100): $1 \mathrm{~S}-34 \mathrm{~S}$.
12. Kanis J, Oden A, Johnell O, et al. The use of clinical risk factors enhances the performance of BMD in the prediction of hip and osteoporotic fractures in men and women. Osteoporosis Int. 2007;18(8):1033-1046.

13. Siminoski K, Leslie WD, Frame H, et al. Recommendations for bone mineral density reporting in Canada. Can Assoc Radiol J. 2005;56(3): 178-188.

14. Yin MT, Shi Q, Hoover DR, et al. Fracture incidence in HIV-infected women: results from the Women's Interagency HIV Study. AIDS. 2010; 24(17):2679-2686.

15. Gertz BJ, Holland SD, Kline WF, et al. Studies of the oral bioavailability of alendronate. Clin Pharmacol Ther. 1995;58(3):288-298.

16. Brookhart MA, Avorn J, Katz JN, et al. Gaps in treatment among users of osteoporosis medications: the dynamics of noncompliance. Am J Med. 2007;120(3):251-256.

17. Siris ES, Harris ST, Rosen CJ, et al. Adherence to bisphosphonate therapy and fracture rates in osteoporotic women: relationship to vertebral and nonvertebral fractures from 2 US claims databases. Mayo Clin Proc. 2006;81(8):1013-1022.

18. Li EC, Davis LE. Zoledronic acid: a new parenteral bisphosphonate. Clin Ther. 2003;25(11):2669-2708.

19. Nancollas GH, Tang R, Phipps RJ, et al. Novel insights into actions of bisphosphonates on bone: differences in interactions with hydroxyapatite. Bone. 2006;38(5):617-627.

20. Dunford JE, Thompson K, Coxon FP, et al. Structure-activity relationships for inhibition of farnesyl diphosphate synthase in vitro and inhibition of bone resorption in vivo by nitrogen-containing bisphosphonates. J Pharmacol Exp Ther. 2001;296(2):235-242.

21. Coxon FP, Helfrich MH, Van't Hof R, et al. Protein geranylgeranylation is required for osteoclast formation, function, and survival: inhibition by bisphosphonates and GGTI-298. J Bone Miner Res. 2000;15(8): 1467-1476.

22. Chen T, Berenson J, Vescio R, et al. Pharmacokinetics and pharmacodynamics of zoledronic acid in cancer patients with bone metastases. J Clin Pharmacol. 2002;42(11):1228-1236.

23. Pietrzik K, Bailey L, Shane B. Folic acid and L-5-methyltetrahydrofolate: comparison of clinical pharmacokinetics and pharmacodynamics. Clin Pharmacokinet. 2010;49(8):535-548.

24. Skerjanec A, Berenson J, Hsu C, et al. The pharmacokinetics and pharmacodynamics of zoledronic acid in cancer patients with varying degrees of renal function. J Clin Pharmacol. 2003;43(2):154-162.

25. Black DM, Delmas PD, Eastell R, et al. Once-yearly zoledronic acid for treatment of postmenopausal osteoporosis. N Engl J Med. 2007; 356(18):1809-1822.

26. Saag K, Lindsay R, Kriegman A, et al. A single zoledronic acid infusion reduces bone resorption markers more rapidly than weekly oral alendronate in postmenopausal women with low bone mineral density. Bone. 2007;40(5):1238-1243.

27. Delmas PD, Munoz F, Black DM, et al. Effects of yearly zoledronic acid $5 \mathrm{mg}$ on bone turnover markers and relation of PINP with fracture reduction in postmenopausal women with osteoporosis. J Bone Miner Res. 2009;24(9):1544-1551.

28. Boonen S, Black DM, Colon-Emeric CS, et al. Efficacy and safety of a once-yearly intravenous zoledronic acid $5 \mathrm{mg}$ for fracture prevention in elderly postmenopausal women with osteoporosis aged 75 and older. J Am Geriatr Soc. 2010;58(2):292-299.

29. McClung M, Recker R, Miller $P$, et al. Intravenous zoledronic acid $5 \mathrm{mg}$ in the treatment of postmenopausal women with low bone density previously treated with alendronate. Bone. 2007;41(1):122-128.

30. Recker RR, Delmas PD, Halse J, et al. Effects of intravenous zoledronic acid once yearly on bone remodeling and bone structure. J Bone Miner Res. 2008;23(1):6-16.

31. Eastell R, Lang T, Boonen S, et al. Effect of once-yearly zoledronic acid on the spine and hip as measured by quantitative computed tomography: results of the HORIZON Pivotal Fracture Trial. Osteoporos Int. 2010; 21(7):1277-1285.

32. Gamsjaeger S, Buchinger B, Zwettler E, et al. Bone material properties in actively bone-forming trabeculae in postmenopausal women with osteoporosis after three years of treatment with once-yearly zoledronic acid. J Bone Miner Res. 2010;25:292-297. 
33. McClung M, Miller P, Recknor C, et al. Zoledronic acid for the prevention of bone loss in postmenopausal women with low bone mass: a randomized controlled trial. Obstet Gynecol. 2009;114(5):999-1007.

34. Grey A, Bolland MJ, Wattie D, et al. The antiresorptive effects of a single dose of zoledronate persist for two years: a randomized, placebo-controlled trial in osteopenic postmenopausal women. J Clin Endocrinol Metab. 2009;94(2):538-544.

35. Lyles KW, Colon-Emeric CS, Magaziner JS, et al. Zoledronic acid and clinical fractures and mortality after hip fracture. N Engl J Med. 2007; 357(18):1799-1809.

36. Boonen SMJ, Lyles K, Colon-Emeric C, et al. Effect of once- yearly i.v. zoledronic acid in men after hip fracture: results from the HORIZON-Recurrent Fracture Trial. Osteoporos Int. 2009; 20(Suppl 1): $\mathrm{S} 23-\mathrm{S} 176$

37. Reid DM, Devogelaer JP, Saag K, et al. Zoledronic acid and risedronate in the prevention and treatment of glucocorticoid-induced osteoporosis (HORIZON): a multicentre, double-blind, double-dummy, randomised controlled trial. Lancet. 2009;373(9671):1253-1263.

38. Orwoll ES, Miller PD, Adachi JD, et al. Efficacy and safety of a once-yearly i.v. infusion of zoledronic acid $5 \mathrm{mg}$ versus a once-weekly 70-mg oral alendronate in the treatment of male osteoporosis: a randomized, multicenter, double-blind, active-controlled study. J Bone Miner Res. 2010;25(10):2239-2250.

39. Ross RW, Small EJ. Osteoporosis in men treated with androgen deprivation therapy for prostate cancer. J Urol. 2002;167(5):1952-1956.

40. Smith MR, Eastham J, Gleason DM, et al. Randomized controlled trial of zoledronic acid to prevent bone loss in men receiving androgen deprivation therapy for nonmetastatic prostate cancer. J Urol. 2003; 169(6):2008-2012.

41. Bhoopalam N, Campbell SC, Moritz T, et al. Intravenous zoledronic acid to prevent osteoporosis in a veteran population with multiple risk factors for bone loss on androgen deprivation therapy. J Urol. 2009;182(5): 2257-2264.

42. Neviaser AS, Lane JM, Lenart BA, et al. Low-energy femoral shaft fractures associated with alendronate use. J Orthop Trauma. 2008; 22(5):346-350.

43. Lenart BA, Lorich DG, Lane JM. Atypical fractures of the femoral diaphysis in postmenopausal women taking alendronate. $N$ Engl J Med. 2008;358(12):1304-1306.

44. Kwek EB, Goh SK, Koh JS, et al. An emerging pattern of subtrochanteric stress fractures: a long-term complication of alendronate therapy? Injury. 2008;39(2):224-231.

45. Goh SK, Yang KY, Koh JS, et al. Subtrochanteric insufficiency fractures in patients on alendronate therapy: a caution. J Bone Joint Surg Br. 2007;89(3):349-353.

46. Giusti A, Hamdy NA, Papapoulos SE. Atypical fractures of the femur and bisphosphonate therapy: a systematic review of case/case series studies. Bone. 2010;47(2):169-180.

47. Shane E, Burr D, Ebeling PR, et al. Atypical subtrochanteric and diaphyseal femoral fractures: report of a task force of the American Society for Bone and Mineral Research. J Bone Miner Res. 2010;25(11): 2267-2294.
48. Rizzoli R, Akesson K, Bouxsein M, et al. Subtrochanteric fractures after long-term treatment with bisphosphonates: a European Society on Clinical and Economic Aspects of Osteoporosis and Osteoarthritis, and International Osteoporosis Foundation Working Group Report. Osteoporos Int. 2011;22(2):373-390. Epub November 18, 2010.

49. FDA. Information on bisphosphonates (marketed as Actonel, Actonel+Ca, Aredia, Boniva, Didronel, Fosamax, Fosamax+D, Reclast, Skelid, and Zometa). http://www.fda.gov/Drugs/DrugSafety/PostmarketDrugSafety InformationforPatientsandProviders/ucm 101551.htm. Accessed November 22, 2010.

50. Black DM, Kelly MP, Genant HK, et al. Bisphosphonates and fractures of the subtrochanteric or diaphyseal femur. $N$ Engl J Med. 2010; 362(19):1761-1771.

51. Woo SB, Hellstein JW, Kalmar JR. Narrative [corrected] review: bisphosphonates and osteonecrosis of the jaws. Ann Intern Med. 2006; 144(10):753-761.

52. Grbic JT, Landesberg R, Lin SQ, et al. Incidence of osteonecrosis of the jaw in women with postmenopausal osteoporosis in the health outcomes and reduced incidence with zoledronic acid once yearly pivotal fracture trial. J Am Dent Assoc. 2008;139(1):32-40.

53. Pazianas M, Miller P, Blumentals WA, et al. A review of the literature on osteonecrosis of the jaw in patients with osteoporosis treated with ora bisphosphonates: prevalence, risk factors, and clinical characteristics. Clin Ther. 2007;29(8):1548-1558.

54. Buckler H, Fraser W, Hosking D, et al. Single infusion of zoledronate in Paget's disease of bone: a placebo-controlled, dose-ranging study. Bone. 1999;24(5 Suppl):81S-85S

55. Reid IR, Brown JP, Burckhardt $P$, et al. Intravenous zoledronic acid in postmenopausal women with low bone mineral density. $N$ Engl J Med. 2002;346(9):653-661.

56. Boonen S, Sellmeyer DE, Lippuner K, et al. Renal safety of annual zoledronic acid infusions in osteoporotic postmenopausal women. Kidney Int. 2008;74(5):641-648.

57. Weinman EJ, Patak RV. Acute renal failure in cancer patients. Oncology (Williston Park). 1992;6(9):47-52; discussion 52-44.

58. Kintzel PE. Anticancer drug-induced kidney disorders. Drug Saf. 2001;24(1):19-38

59. Health Canada. Updated Renal Safety Information on Zometa (Zoledronic Acid) and Aclasta (Zoledronic Acid). http://www.hc-sc.gc.ca/dhp-mps/ medeff/advisories-avis/public/_2005/zometa_aclasta_pa-ap-eng.php. Accessed January 24, 2011.

60. Orwoll ES. Osteoporosis in men. Primer on the Metabolic Bone Diseases and Disorders of Mineral Metabolism. In: Favus MJ, editor. Washington, CD: American Society for Bone and Mineral Research; 2003:360-364.

61. Orwoll E, Miller P, Adachi J, et al. Once-yearly IV zoledronic acid $5 \mathrm{mg}$ versus weekly oral alendronate $70 \mathrm{mg}$ in men with osteoporosis. In: ENDO 2009 Abstracts2View Online. Abstract OR13-3. Chevy Chase, MD: The Endocrine Society; 2009. http://www.endo-society. org/endo09/. Accessed January 24, 2011.

62. McCombs JS, Thiebaud P, McLaughlin-Miley C, Shi J. Compliance with drug therapies for the treatment and prevention of osteoporosis. Maturitas. 2004;48(3):71-287.
Clinical Interventions in Aging

\section{Publish your work in this journal}

Clinical Interventions in Aging is an international, peer-reviewed journal focusing on evidence-based reports on the value or lack thereof of treatments intended to prevent or delay the onset of maladaptive correlates of aging in human beings. This journal is indexed on PubMed Central, MedLine, the American Chemical Society's 'Chemical Abstracts

\section{Dovepress}

Service' (CAS), Scopus and the Elsevier Bibliographic databases. The manuscript management system is completely online and includes a very quick and fair peer-review system, which is all easy to use. Visit http://www.dovepress.com/testimonials.php to read real quotes from published authors. 